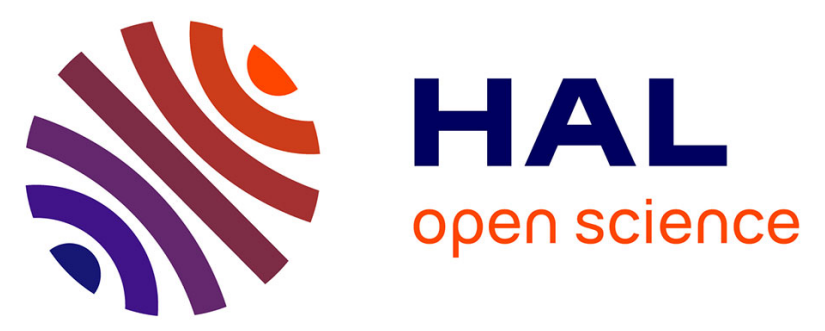

\title{
Developping patterns as a mechanism for assisting the management of knowledge in the context of conducting organisational change
}

Nikos Prekas, Pericles Loucopoulos, Colette Rolland, Georges Grosz, Farida Semmak, Danny Brash

\section{To cite this version:}

Nikos Prekas, Pericles Loucopoulos, Colette Rolland, Georges Grosz, Farida Semmak, et al.. Developping patterns as a mechanism for assisting the management of knowledge in the context of conducting organisational change. Database and Expert Systems Applications, 1999, Florence, Italy. pp.110 122, 10.1007/3-540-48309-8_10 . hal-00707619

\section{HAL Id: hal-00707619 \\ https://hal.science/hal-00707619}

Submitted on 17 Jun 2012

HAL is a multi-disciplinary open access archive for the deposit and dissemination of scientific research documents, whether they are published or not. The documents may come from teaching and research institutions in France or abroad, or from public or private research centers.
L'archive ouverte pluridisciplinaire $\mathbf{H A L}$, est destinée au dépôt et à la diffusion de documents scientifiques de niveau recherche, publiés ou non, émanant des établissements d'enseignement et de recherche français ou étrangers, des laboratoires publics ou privés. 


\title{
Developping patterns as a mechanism for assisting the management of knowledge in the context of conducting organisational change
}

\author{
Nikos Prekas ${ }^{1}$, Pericles Loucopoulos \\ Department of Computation, UMIST \\ P.O. Box 88 \\ Sackville Street \\ Manchester M60 1QD \\ U.K. \\ Phone: +44-161-200 3382 \\ Fax: +44-161-200-3324 \\ e-mail: \{prekas|pl\}@co.umist.ac.uk
}

\section{Colette Rolland, Georges Grosz, Farida Semmak}

Centre de Recherche en Informatique

UFR27

Universite Paris 1 Pantheon-Sorbonne

90, rue de Tolbiac

F-75634 PARIS CEDEX

France

Phone: +33-1-40 774634

Fax: +33-1-40 771954

e-mail: \{rolland|grosz|semmak\}@univ-paris1.fr

\section{Danny Brash}

Department of Computer and Systems Sciences Stockholm University/Royal Institute of Technology

Electrum 230

S-164 40 KISTA

Sweden

Phone: +46-8-16 1618

Fax: +46-8-7039025

e-mail: danny@dsv.su.se

\footnotetext{
${ }^{1}$ To be used as contact person.
} 


\title{
Developping patterns as a mechanism for assisting the management of knowledge in the context of conducting organisational change
}

\begin{abstract}
In a business environment that is constantly evolving the management of knowledge is becoming increasingly important. In particular the shareability and repeatability of experience gained in change situations can prove an invaluable tool for the evolving enterprise. We advocate the use of the pattern paradigm as a means to capture and disseminate this type of knowledge. The patterns that we propose are organisational design proposals, where particular emphasis is placed on representing two complementary aspects of change: the ways in which an enterprise can conduct change (the process of change), and the possible states to which this change leads the enterprise (the product of change). Our approach to pattern development is based (a) on the existence of a pattern template and (b) on a cooperative and discussant way of working, so as to ensure that a maximum of knowledge relevant to the domain of interest is captured. The approach is illustrated with examples from a study of change management in the electricity sector, where it is currently being applied.
\end{abstract}

\section{Introduction}

Today's turbulent business environment requires organisations to modify and extend their traditional practices. Businesses now have to undertake change and transform themselves into adaptive enterprises able to respond to increasing complexity and uncertainty. Conducting change in an organisation is not a straightforward task. Experience has shown that change is only possible, when those involved engage in an incremental and managed change process.

Change management is primarily about affecting how people work. This places an emphasis on changing behaviour and sets a demand for adopting the right practices in order to achieve preferred behaviour. The organisational context which supports the preferred behaviour should be enhanced [Scarbrough 1996]; this move needs positive 
reinforcement, as everybody involved needs to be convinced of the advantages to themselves [Kautto-Koivula 1998]. In this demanding and ever evolving setting, the sharing and management of knowledge become essential, as change more often than not encompasses multiple aspects and domains of a business environment. A global and thorough understanding of the situations at hand is therefore required before embarking on the process of change, but also during the process and after its completion.

In this paper we advocate the use of patterns as a mechanism for assisting the management of knowledge in situations of change, and the dissemination of experience gained from similar situations. The framework that we propose is based on a view of patterns as organisational design proposals that can be repeatedly used in different enterprise settings. The pattern framework presented here draws on the existence of a wider knowledge management methodology, namely the Enterprise Knowledge Development methodology (EKD) [Bubenko et al. 1997; Loucopoulos et al. 1997], and on the application of this methodology in the case of deregulation in the Electricity Supply Industry (ESI) sector. This research is part of the ongoing European research project ELEKTRA, which aims to tailor a methodology for managing change in ESI companies and to discover patterns of change management for reuse in the sector.

The paper is structured as follows: Section 2 presents an overview the pattern concept. Section 3 presents the significance of patterns in the enterprise setting, while Section 4 completes this view by presenting how to encapsulate knowledge in the pattern template. In Section 5 we present the use of patterns in change management, and in Section 6 we explain the way-of-working for developing patterns. Section 7 gives an 
example from the case studies performed in ELEKTRA, while Section 8 concludes with a summary and our directions for future work.

\section{Background to patterns}

Recent years have witnessed an increasing interest in the use of patterns within the software development community and in particular by those advocating and practising object-oriented approaches and re-use. This recent interest in patterns has its origins in [Coad 1992] and has subsequently permeated into software programming [Buschmann et al 1996; Beck 1997], software and system design [Coplien and Schmidt 1995; Gamma et al. 1995; Vlissides et al 1996; Eriksson and Penker 1998], data modelling [Hay 1996] and more recently into systems analysis [Fowler 1997].

Much of the contemporary work on patterns has been inspired by the work of Christopher Alexander who wrote a seminal book on the use of patterns within the domain of architecture. This book, 'The Timeless Way of Building' [Alexander 1979] sets the scene on the importance of patterns in such a way that, in many respects, it transcends the field of architecture. Alexander presents in this book the main arguments for the discovery of patterns and their use for achieving quality of designs. He defines a pattern as describing "a problem which occurs over and over again in our environment and then describes the core of the solution to that problem, in such a way that you can use this solution a million times over, without ever doing it the same way twice" [Alexander et al. 1977]. Here, the emphasis is put on the fact that a pattern describes a recurrent problem and it is defined with its associated core solution. 
The use of patterns outside architecture has been successful partly due to their interpretation by Alexander. According to this interpretation, buildings, towns, communities, enterprises, software, and so on, can be understood and developed in terms of their patterns of relationships. In terms of enterprise development and change management, Coplien argues that "patterns should help us not only to understand existing organisations but also to build new ones" [Coplien 1995a; Coplien 1995b].

The utility of the pattern concept lies primarily in the fact that it allows past experience to be made easily available. This makes patterns an ideal concept in human endeavours that involve design and the kind of decisions that come with it. As argued in [Coad 1992], "finding and applying patterns indicates progress in a field of human endeavour". The progress lies in the fact that by developing a pattern, domain practitioners condense part of their knowledge on current domain practice and make it available to others. In fact, a pattern can convey best practice in a domain, practice that has proved sound and efficient, and can therefore be disseminated. When other practitioners subsequently reuse this pattern, they benefit from the experience of the pattern designers.

\section{Patterns as organisational solutions}

Although patterns have been applied for some time to the software engineering domain, and in particular with respect to object technologies [Coad 1992; Coplien and Schmidt 1995; Gamma et al 1995; Eriksson and Penker 1998], there has not been any significant application in the organisational and business domain. The idea of developing and reusing patterns to solve recurring business problems is relatively new. There are no 
standard components for use in the enterprise world, mainly because there is no standard framework for that area. As more emphasis is put on the management of change, and as the focus of attention in the IT community is shifting from software engineering to business engineering and the integration of business with IT, this situation is starting to change. The analysis patterns, for instance, that are presented in [Fowler 1997], are as much business-oriented as they are software-oriented.

Patterns in the enterprise setting can be used to describe anything that presents regular, repeatable characteristics: formal organisational and contractual relationships, informal relationships, responsibilities, work practices etc. In electricity companies, for instance, there is usually a business process dedicated to the collection of data on customer consumption of electricity. We can represent this knowledge as the Meter Reading business process pattern.

While in the traditional pattern literature a pattern is described as a tested solution to a problem, in EKD we use this term with a slight variation in meaning. Our study is focused on the enterprise setting, therefore the patterns that we propose are essentially organisational designs. These designs are solutions to specific problems within the context of an organisation, problems that are important and recurring in a variety of cases. Whereas it is possible to argue that some of these designs are tried and tested throughout a sector, some others will only be proposals for organisational solutions, whose degree of applicability will need to be tested. Therefore, in the scope of our approach we place the emphasis on the fact that patterns are generic and abstract design 
proposals, solutions to recurring problems within the sector of interest, that can be easily adapted and reused (see Figure 1).

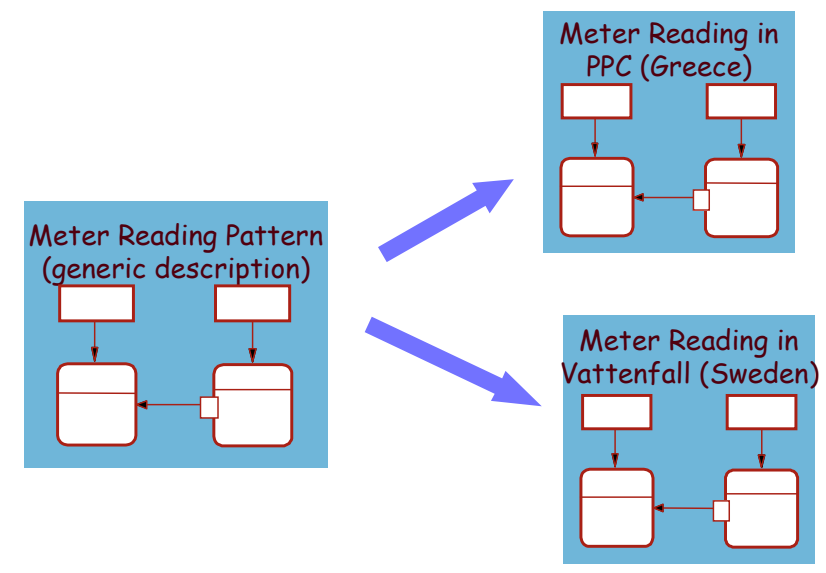

Figure 1: Reusability of patterns in different enterprise settings

\section{Encapsulating organisational knowledge in patterns}

In developing patterns, we place equal emphasis on developing knowledge components that are meaningful in themselves and on providing enough information about these components so as to make them effectively reusable. Thus we aim to produce a set of patterns that propose useful solutions to recurring problems and at the same time to describe these patterns in a way that guides and supports the reuse process.

We therefore make the distinction between the body of a pattern and its descriptor (see Figure 2); together these two constitute the pattern template (see also [Grosz et al 1998; UP1-UMIST 1998]). The former is the part of the knowledge that is effectively reused (knowledge perspective) whereas the latter aims to provide sufficient information on the pattern and to describe the context in which the body of the pattern can be reused (usage perspective). 
A pattern is thus completely defined by its descriptor and its body. In our framework the body of the patterns is in most cases an EKD model fragment, i.e. the patterns that we develop are cognisant of the semantics of the EKD methodology. In case that an EKD model is not available or feasible, the pattern can be described by natural language or a multimedia element (e.g. a drawing, a video etc.).

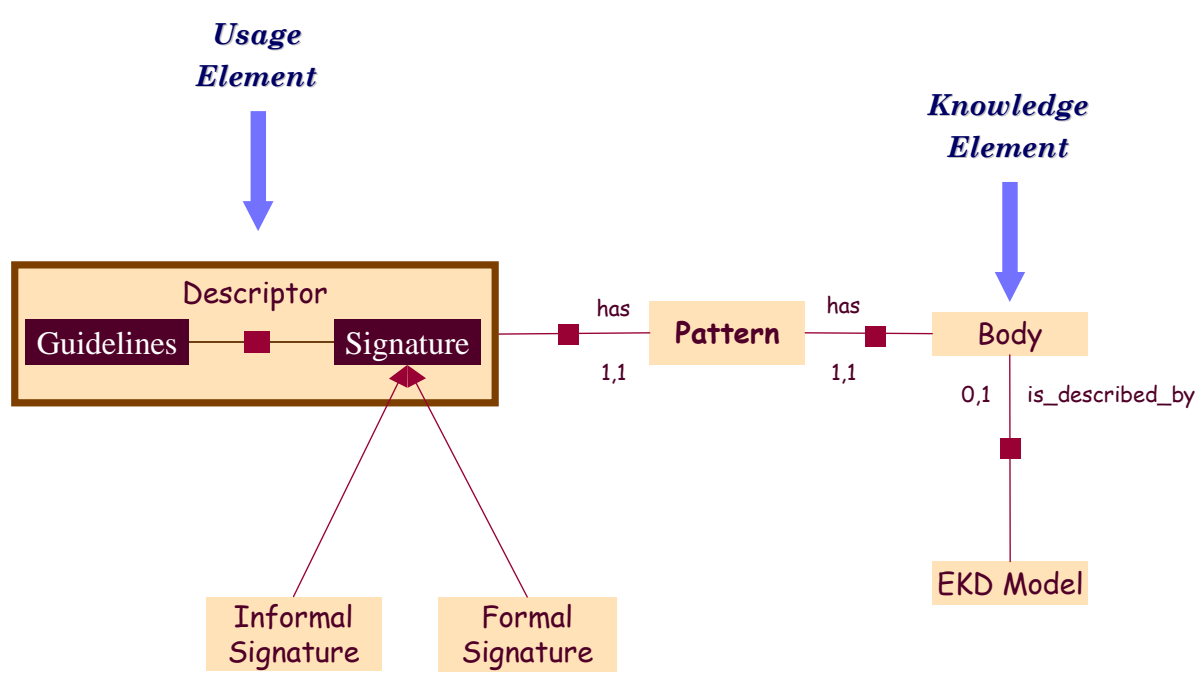

Figure 2: The pattern template

As far as the descriptor is concerned, it consists of

- the formal signature

- the informal signature, and

- the guidelines.

The formal signature is necessary during the reuse process in order to retrieve patterns which are appropriate for a given situation having a given usage intention in mind. A formal signature comprises the domain of activity where the pattern applies, the type of 
the pattern and the usage intention of the pattern. For describing the formal signature, we use formalised natural language.

The informal signature of a pattern contains detailed information about the problem at hand and the proposed solution; it is composed of mandatory and optional components. The mandatory components include the name of the pattern, the context of its application, the problem that it is trying to solve, the forces characterising the problem and the solution to the problem. The optional components are the consequences of applying the pattern, the rationale behind the solution, related patterns or documents, hyperlinks and known applications of the pattern, as well as additional annotations.

Each pattern should reflect its applicability conditions within a real situation. This is achieved through pattern guidelines. The guidelines are usage tips to the potential user of the pattern about how the pattern can be tailored to fit into particular situations or needs. In a sense, using EKD terms, the guidelines aim to give an idea of how the pattern can be tailored to create an enterprise model. The informal signature and guidelines are represented using free natural language.

Figure 3 presents an example of a pattern, the Meter Reading pattern. This pattern is of Actor-Role type, a modelling mechanism devised to represent organisational and operational affinities in an enterprise setting ${ }^{2}$. All the elements of the pattern template can be seen in this example (only the mandatory components of the informal signature are shown). 


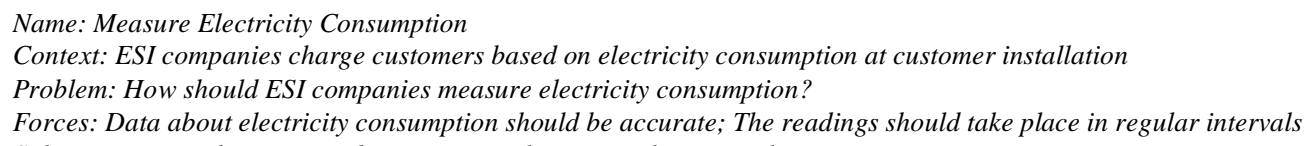

Context: ESI companies charge customers based on electricity consumption at customer installation

Problem: How should ESI companies measure electricity consumption?

Forces: Data about electricity consumption should be accurate; The readings should take place in regular intervals

Solution: Ensure that meter indications are taken in regular intervals

Guidelines : Depending on the target organisation, the actor «Distribution Division» and its associated role may be splitted into a set of actors and a set of associated roles reflecting the structure of the organisation. This also applies to the «Meter Reader» actor and its role. Coordination links will have to be defined between the roles resulting of the splitting. However, these new links have to conform to the coordination needs between the roles «Meter reading management» and «Meter reading»:

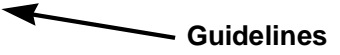

Type: $\{$ Actor-Role Diagram $\}$

Domain: Customer Servicing

Usage Intention: Define ${ }_{\text {verb }}(\text { Meter Reading })_{\text {target }}$

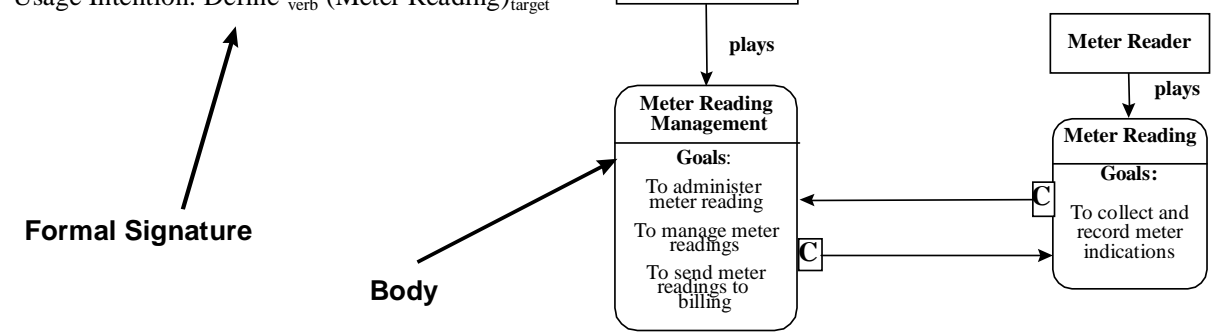

Figure 3: A complete description of the Meter Reading pattern

We have placed much emphasis in organising patterns using a meaningful and coherent mechanism. By organising and storing the patterns we develop a knowledge base for the domain of interest (what in other pattern frameworks has been termed the pattern language); thus for the ELEKTRA project, the outcome is a knowledge base for change management in ESI.

The mechanism that was preferred for pattern organisation is that of a hierarchy [Grosz et al 1998]. The hierarchy of patterns is built using the formal signature of the patterns, and specifically by associating the usage intentions of patterns. The pattern hierarchy is therefore organised in an intentional manner. This mechanism facilitates the storage and

\footnotetext{
${ }^{2}$ More on Actor-Role Modelling can be found in [Loucopoulos et al. 1997].
} 
retrieval of patterns through an on-line pattern repository (more on this issue can be found in [Rolland et al. 1998a; Rolland et al. 1998b]).

\section{Using patterns in change management}

There has been an increasing interest over the years in understanding organisational change and managing it in a structured and systematic manner [Medina-Mora et al. 1992; Davenport 1993; Lee 1993; Yu 1994; Ould 1995; Wieringa 1996; Hsiao and Ormerod 1998]. The pressure on the enterprise world to move towards leaner and more efficient business solutions has led to the development of increasingly sophisticated change management frameworks.

In our approach [Kavakli and Loucopoulos 1998; Rolland et al 1998c], in order to deal with the task of consistently and systematically managing change, we impose upon the activity of conducting change the view of the process-product cycle (see Figure 4). The essence of this view is that an initial state of affairs gives rise to an intention for change; this change intention can lead to a new state of affairs through a set of alternative ways of achieving change. The way of conducting the change is the process, while the states that we start from and arrive to are the products. This cycle is intention-driven in that it is triggered by the needs for change that characterise the initial state of affairs. 


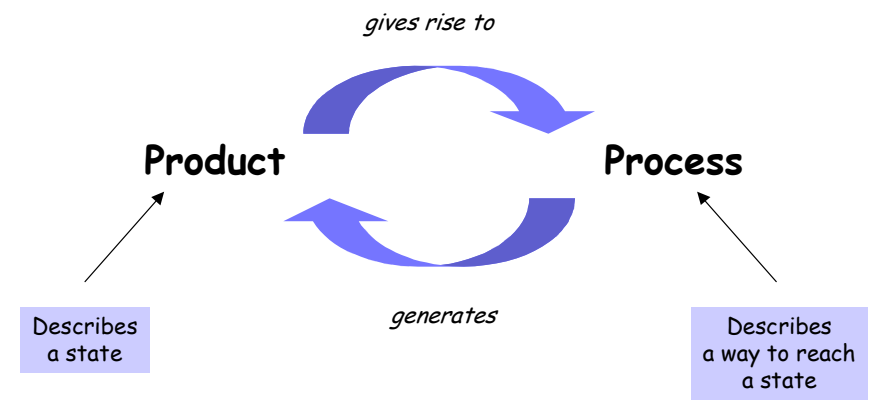

Figure 4: The product-process cycle in change management

What we want to achieve through the development of patterns is to ensure the repeatability of the process-product cycle. This involves identification of possible products (or states) that can be of interest to organisations in the domain of interest and of repeatable processes that can be followed to reach these states. In other words, we aim to disseminate the experience that we gain by applying the EKD methodology in a change management case. In ELEKTRA, our interest has focused on the ESI sector, and in particular on identifying 'generalised patterns of change management for re-using them in similar settings in other electric supply companies'.

EKD addresses both the description of the enterprise (in terms of organisational, operational, and informational components) and the description of the change process itself. This leads to the definition of two types of patterns:

- Patterns dedicated to modelling the change process in the domain of interest. We call these change process patterns. Change process patterns refer to the transition process, the choices and alternatives that one may have in reaching an objective. We use an extended goal model as a means to represent the body of change process patterns. The transition process, therefore, is viewed as a teleological process whereby the goal graph is a model of the design process. 
- Patterns dedicated to modelling the domain of interest itself. We call these product patterns. Product patterns are further subdivided into types, according to the modelling aspect of EKD that they convey; thus, we can have goal patterns, actorrole patterns, business rule patterns etc.

This dual nature of patterns is illustrated in Figure 5 and directly reflects the view of change management outlined above. Product patterns on one hand, can be used to describe a state of affairs (whether it is the current or the future one), i.e. a way in which the enterprise can conduct its business. Change process patterns on the other hand, can express the ways in which a transition from one state to another can be achieved.

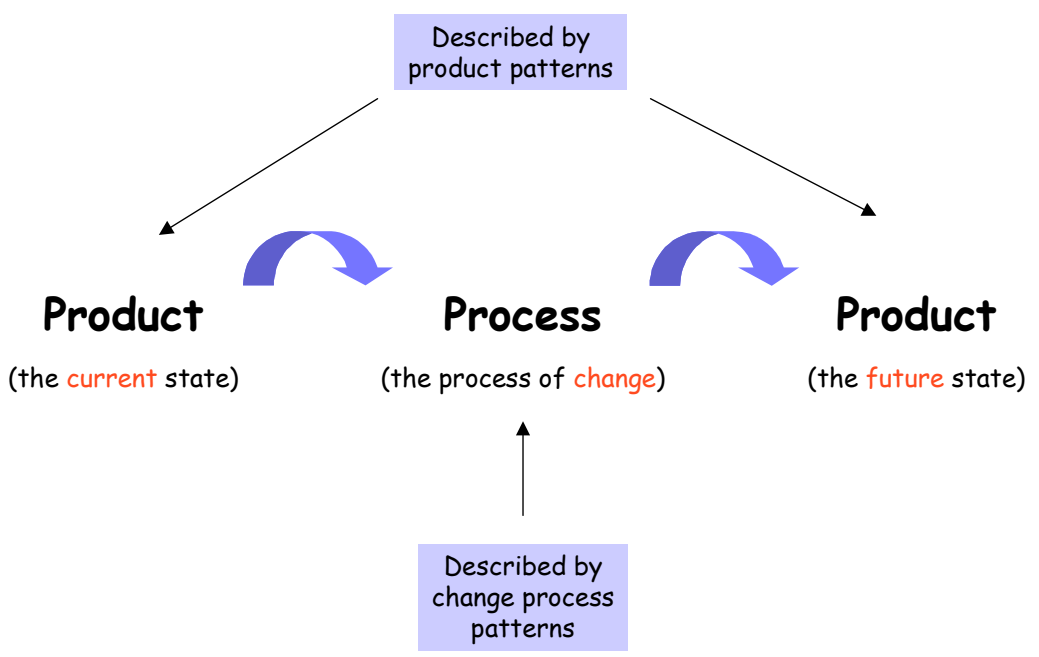

Figure 5: The role of patterns in change management

Under this view, a change process pattern constitutes a proposed solution to the problem of designing a new situation by describing the steps necessary for the implementation of the new situation, i.e. by offering a way of achieving the future state of affairs. A product pattern on the other hand describes the situation itself by detailing individual aspects of the business involved. Product patterns and change process patterns can then 
be viewed as complementary elements, in that each type of pattern solves smaller-scale problems within the greater design problem.

Let us consider an example from the case of change in the ESI sector. In the new international setting of the electricity market, an electricity company may operate in a competitive environment where multiple electricity producers and suppliers exist. The company's Supply division (dealing with the retailing of electricity to consumers) will need to establish a business process for procuring electricity from the producers in order to sell it to the consumers. Figure 6 shows the change process pattern Introduce the buying and selling of electricity, which illustrates the options of how the company can implement this process.

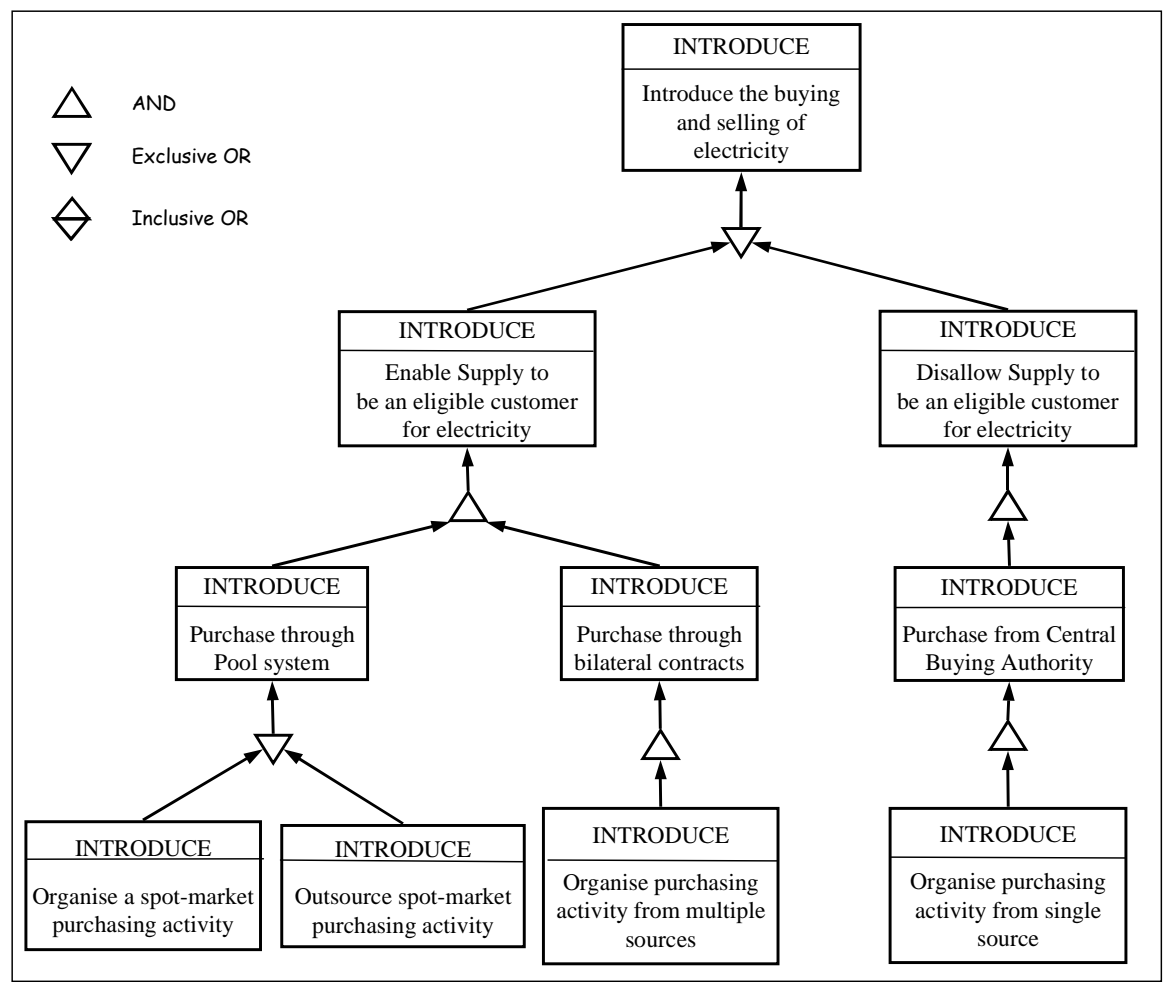

Figure 6:Change process pattern dealing with the trading of electricity 
The pattern has the form of a goal graph where the leaf goals represent four alternative ways (mutually exclusive in this case) of organising an electricity procurement business process. The third leaf goal of the change process pattern, for instance, proposes the introduction of a purchasing activity from multiple sources. The details of how such an activity can be configured are presented in Figure 7; here a product pattern is shown that explains the buying-and-selling activity when multiple sources of electricity are involved. While each of these two patterns has its own complete meaning and can be used independently, together they constitute a design proposal for answering a greater problem in the electricity sector.

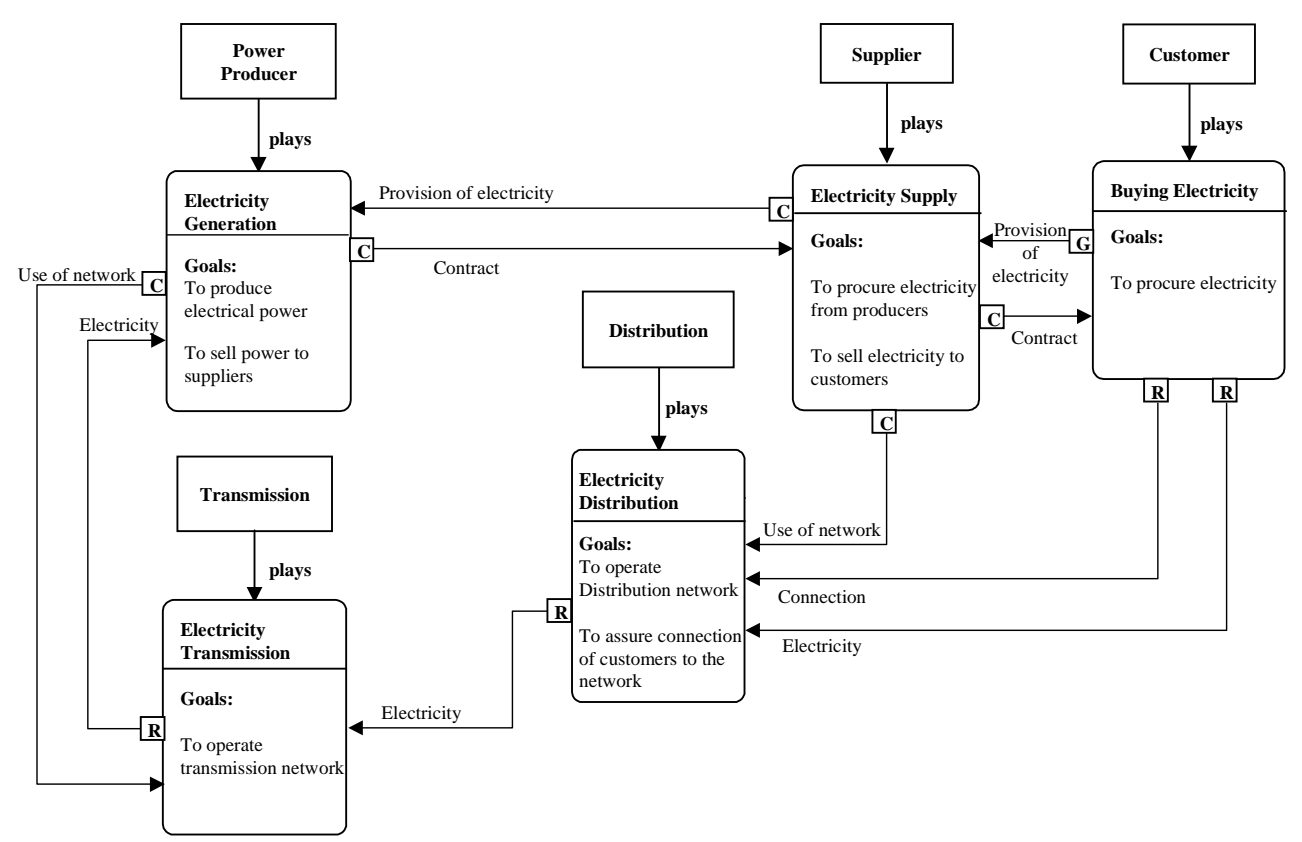

Figure 7: Product pattern (Actor-Role) dealing with the trading of electricity with multiple sources of procurement

\section{The way-of-working for developing patterns}

The main benefit of pattern development is reusability. A pattern is a component whose purpose is to be reused whenever a problem arises that matches the context of the 
pattern. The process of reuse can be divided into two activities [Bellinzona et al. 1993; DeAntonellis and Pernici 1995]. The first one deals with the process of defining reusable components (known as Design for reuse), the second concerns the effective usage of the reusable components (known as Design by reuse). In this paper, we concentrate on the activity of 'design for reuse'.

Developing patterns that encapsulate enterprise knowledge is a task of increased complexity. Knowledge pertinent to a domain, sometimes only implicitly and vaguely defined, needs to be captured and correctly represented. When considering the case of change management in particular, additional constraints are prevalent. The conditions that characterise the change process need to be clearly identified, so that the applicability of the patterns in similar cases can be determined. Thus, the context of the particular situation at hand, and the potential directions for change have to be captured.

In order to tackle these demands, we devised a process of developing patterns that is iterative and involves domain experts and method experts (analysts) in close cooperation. The process consists of the following four steps:

1. Elicitation of candidates

2. Suitability evaluation

3. Documenting

4. Verification 
We will now briefly examine each step of the process ${ }^{3}$.

\section{Step 1: Elicitation of candidates}

Collecting candidate patterns aims at identifying potential change process patterns and product patterns that will be considered for inclusion in the knowledge base. The objective is to describe a pattern at a sufficient level of detail in order to proceed to its evaluation. The output of the elicitation process is a list of candidate patterns each having an initial description of major components: name, problem, solution and context along with a first draft of its formal signature and body.

Potential sources of knowledge for initial elicitation of patterns range from enterprisespecific documentation (e.g. current state models of a particular company) to domainwide documentation (e.g. documents describing practice in more than one settings). An important source of candidate patterns can be the not-yet documented knowledge of various domain experts involved in the process.

\section{Step 2: Suitability evaluation}

The candidate patterns obtained as a result of step one need to be evaluated by domain experts so that their further development can be decided upon. The evaluation consists of the following actions:

- Grading the pattern

- Deciding on the suitability of the pattern

- Correcting the pattern

\footnotetext{
${ }^{3}$ A more detailed description can be found in [Molière 1999].
} 


\section{Grading the pattern}

Grading is based on three criteria: usefulness (the candidate pattern addresses an important problem in the domain of interest), quality (the proposed solution effectively addresses the problem) and cost (the cost of implementing the proposed solution). For each criterion, a set of sub-criteria is defined, which helps to evaluate the candidate in detail. The domain experts grade the pattern according to these criteria, giving values of "high", "medium" or "low". A set of decision tables is then used in order to summarise the voting results into a single score per criterion.

\section{Deciding on the suitability of the pattern}

The decision on whether a candidate pattern is accepted for further development or rejected is based on a global numerical score. Table 1 presents the translation of the scores of the previous step into numerical values.

\begin{tabular}{|l|l|l|l|}
\hline Value & High & Medium & Low \\
\hline Usiterion & & & \\
\hline Quality & 2 & 1 & 0 \\
\hline Cost & 0 & 1 & 0 \\
\hline
\end{tabular}

Table 1: Numerical values associated to the scoring of each criterion

The global rating of each pattern is the sum of the numeric values of each criterion, ranging from 0 to 6 . The pattern is accepted if the global rating of a candidate pattern is greater than or equal to 4 . The pattern needs to be corrected if the global rating of a 
candidate pattern is between 2 and 4. Finally, the pattern is rejected if the global rating of a candidate pattern is less than or equal to 2 . These values can be negotiated and agreed upon among the participants.

\section{Correcting the pattern}

If the global rating of a pattern falls between 2 and 4, it needs to be corrected. For each criterion we define a set of corrective actions that give guidelines about how to improve the pattern. When the corrective actions have been performed, the pattern is reevaluated.

\section{Step 3: Documenting}

At this stage the pattern template needs to be completed. More precisely, the domain experts, in co-operation with the analysts now provide the remaining elements of the informal signature (i.e. forces, rationale, consequences etc.) and a set of initial guidelines. The formal signature is also finalised at this stage, which allows the pattern to be included in a hierarchy based on its usage intention. The pattern is now part of the knowledge base and any relationships with other patterns become apparent and explicit.

\section{Step 4: Verification}

After a pattern has been fully described (i.e. all components of the pattern template have been described), the pattern is verified by domain experts. The wording of all elements in the pattern template is carefully studied and modified if necessary, as are interconnections between related patterns. 


\section{Applying the Methodology in the ELEKTRA Project}

In the context of ELEKTRA, we have concentrated on the study of change in the domains of Distribution and Human Resource Management of electricity companies. In developing a pattern knowledge base we used information from the various phases of the ELEKTRA project (detailed in the form of EKD models in [Athena 1997; Carolus 1998; Demetra 1998; Freja 1998]), knowledge about practice in the ESI sector world-wide [Prekas et al. 1998], and current understanding of domain experts involved in the project.

We have found one of the main contributions of patterns to the management of organisational change to be that they may supply decision-makers with semi-structured information in the face of choosing between alternatives. Since these alternatives are organised in an intentional hierarchical structure, browsing through them is more intuitive than, say, relational or object-oriented database searching. Problems and solutions are searched for according to hierarchies defined by the domain experts. This can make a difference in the case of participants that are not expert computer users, as is often the case with management personnel.

\section{Description of the change problem - The case studies}

Before the move for deregulation of the electricity sector started, it was often the case that electricity companies operated as utilities rather than as commercial enterprises, one of their main characteristics being vertical and horizontal integration. With the introduction of competition and the reduction of extensive regulation, this situation has started to change. Today, electricity companies in Europe and worldwide often need to reinvent themselves by building a profile based on market principles and/or by splitting 
into independent organisational entities, each dealing with a different aspect of the electricity market (e.g. Generation dealing with the production of electrical power, and Supply dealing with the retailing of power to consumers). This changing environment has created a pressure on electricity companies to adapt many practices and structures; these pressures have had an impact on almost all aspects of business, though expressed in different ways in Distribution and in Human Resource Management.

In ESI sector terms, Distribution deals with the low voltage network carrying electricity to the sites of consumers and often it also comprises the retailing of electricity to customers (a domain otherwise known as Supply). In integrated electricity companies, Distribution and Supply have often been bundled with other activity areas (e.g. Generation, Transmission). The move for deregulation now requires them to become separate organisational entities or different companies altogether. As a consequence, the patterns that we developed for Distribution reflect the possible moves that a company starting from the status of a public utility (i.e. monopoly rights, extensive bundling) can carry out in order to adapt to an environment where monopoly is abolished and competition prevails.

As the electricity market in Europe is being deregulated, new skills, competencies and knowledge are needed; this greatly affects the way in which electricity companies conduct Human Resource Management. Changes need to be made in how companies traditionally deal with these issues in terms of organisation, processes and decisionmaking. The human resource management patterns developed so far reflect the need for change at all levels of the organisation, towards more integration, co-operation, and co- 
ordination. The relatively large size and degree of division of an electricity company can lead to the creation of "islands of knowledge" in terms of competency-related activities. In practice, there is a trade-off between an increased degree of divisional independence, which improves creativity and response times, and increased centralisation, which improves co-ordination and co-operation.

\section{An example}

As an example of applying the methodology, we shall detail the development of the change process pattern Introduce structural unbundling, taken from the Distribution case study.

This pattern addresses a significant problem of the Distribution division of an ESI company, with respect to deregulation and customer servicing. Specifically, an understanding is needed of how a horizontally and vertically integrated ESI company can undertake steps towards entering a deregulated and competitive electricity market. This is representative of the kind of thinking required for developing patterns in such an environment. The knowledge of the needs for reform gained during previous phases of the project offered the pattern developers an informed view of the issues that are likely to be of importance in this situation.

\section{Elicitation}

The choice of candidate pattern was driven by what was considered as being essential toward the evolution of the ESI sector with respect to the deregulation rules being applied in the European Union. Existing EKD models, developed during earlier phases 
of the project, were used as the source of knowledge for this pattern. Initially, the elements of the informal signature were identified as:

Problem: An electricity distribution company in a monopoly environment must enter into a competitive market.

Context: The management of the wire and supply businesses of Distribution is currently fully integrated. All business-related activities are handled internally. The proposed services are restricted to electricity supply.

Forces: The deregulation rules for the European electricity market issued by the Commission of the EU force an electricity distribution company functioning as a monopoly to enter a competitive market.

The initial version of the solution suggested considering four aspects of unbundling:

- wire business and customer services are unbundled,

- new technical services other than electricity are introduced,

- outsourcing of customer and wire services are considered,

- new customer services not related to electricity are introduced.

These can be seen in Figure 8, where the initial version of the pattern body is presented. 


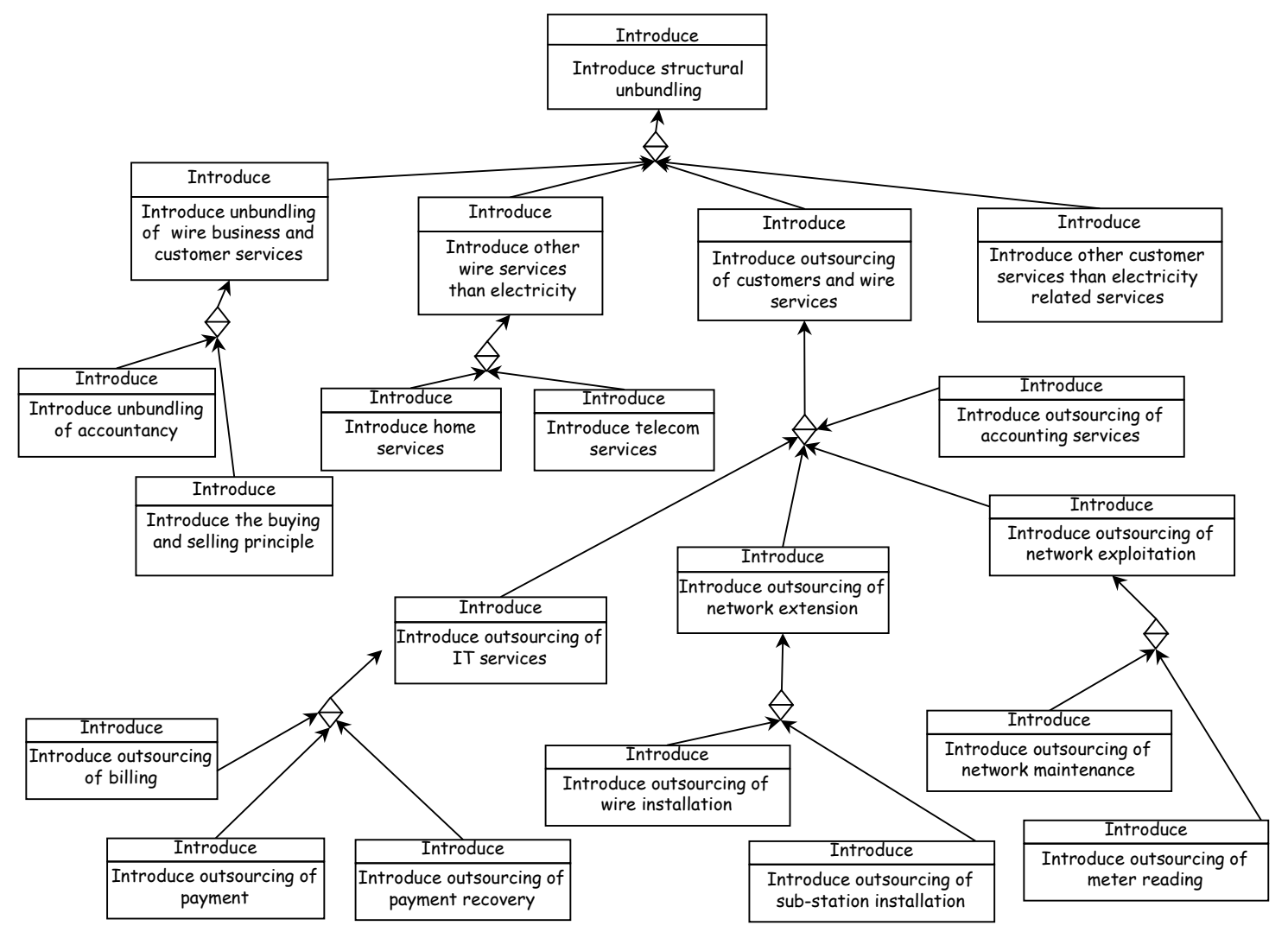

Figure 8: The initial version of the pattern body

\section{Evaluation}

The pattern was evaluated by domain experts with knowledge of strategy issues. The pattern was deemed as an important contribution to the ESI knowledge base because it addresses an essential problem in deregulation of electricity companies. During the evaluation corrective actions were proposed, particularly with respect to introduction of new services (both wire-based and customer-oriented ones). Some information related to outsourcing of services was removed, as it was deemed trivial.

As an interesting result of the evaluation process, the participants noticed the need to introduce a completely new pattern, complementary in nature, namely Introduce new means to increase market share. This pattern was deemed important because it 
suggests a strategic view of how to face the results of structural unbundling and the introduction of competition. We will not, however, go into detail concerning this pattern here.

\section{Documenting/Verification}

After further discussions it was decided that part of the pattern, dealing with the introduction of new services, contained sufficient information to be treated as separate patterns. The final version of the body of the pattern is presented in Figure 9. The remaining information is now contained in two additional change process patterns
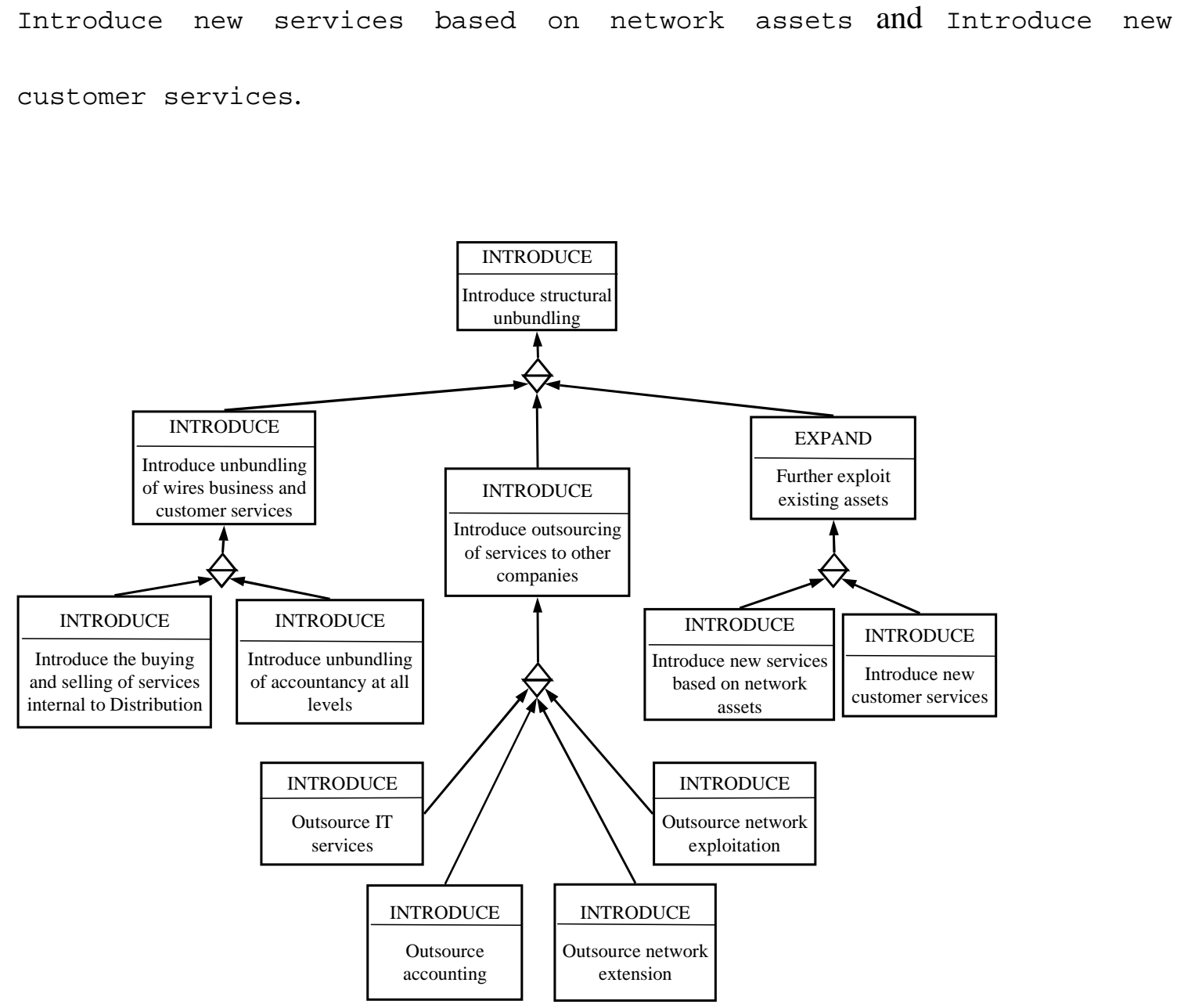

Figure 9: The final version of the pattern body 


\section{Summary - Future Work}

Managing change in organisations is becoming a crucial issue due to the rapid change of today's business. To this end, we propose patterns as a means to assist in the management of knowledge in change situations. The result of our work takes the form of a framework where a pattern contains an organisational design proposal that can be re-used in different enterprise settings. These proposals are based on the EKD methodology. As illustrated in this paper, we have applied the framework in the context of the European research project ELEKTRA for supporting change management in two particular domains of the Electricity Supply Industry sector.

A pattern couples a problem to a solution. The problem is described within the pattern descriptor whereas the solution, the organisational design proposal, constitutes the body of the pattern. We consider two types of patterns: change process patterns and product patterns. A change process pattern suggests how to conduct and manage the process of change in an organisation, whereas a product pattern describes a (part of the) solution implemented by the change. While each type of pattern has its own complete meaning and can be used independently, together they constitute a coherent and comprehensive solution for managing organisational changes. Patterns are organised within hierarchies that facilitate search and retrieval.

Using the proposed framework, a set of patterns has been developed for managing change in the Distribution and Human Resource Management domains of electricity companies (presented in [Molière 1999]). We are currently working on defining how 
patterns can be effectively reused ('design by reuse' activity). The final objective of our work concerns the implementation of the proposed framework within a consultancy toolset for change in the ESI sector [Ikarus 1998]. We are also envisioning means for disseminating the knowledge embedded within the patterns through the WWW [Rolland et al. 1998a; Rolland et al. 1998b].

\section{Acknowledgements}

The research presented in this paper has been funded by the European research project ELEKTRA (ESPRIT project no. 22927). The authors wish to thank all the partners involved in the project for their cooperation and contribution to the results, and especially the participants from the two user companies, the Public Power Corporation of Greece and Vattenfall of Sweden. We also thank our colleague Vagelio Kavakli for her useful comments and recommendations.

\section{References}

[Alexander et al. 1977] C. Alexander, S. Ishikawa, M. Silverstein, M. Jacobson, I. FiksdahlKing, S. Angel A Pattern Language, Oxford University Press, New York, 1977.

[Alexander 1979] C. Alexander The Timeless Way of Building, Oxford University Press, New York, 1979.

[Athena 1997] Athena: Initial Requirements Model for PPC ELEKTRA Project Deliverable Document, September 1997.

[Beck 1997] K. Beck Smalltalk Best Practice Patterns, Volume 1: Coding, Prentice Hall, Englewood Cliffs, NJ, 1997. 
[Bellinzona et al. 1993] R. Bellinzona, M.G. Fugini and V. de Mey Reuse of Specifications and Designs in a Development Information System, Information System Development Process (A30), N. Prakash, C. Rolland and B. Pernici (Eds.), IFIP, Sept. 1993.

[Bubenko et al. 1997] J. Bubenko, D. Brash and J. Stirna EKD User Guide, ELEKTRA Project Report, February 1997.

[Buschmann et al. 1996] F. Buschmann, R. Meunier, H. Rohnert, P. Sommerland and M. Stal Pattern-Oriented Software Architecture - A System of Patterns, John Wiley, 1996.

[Carolus 1998] Carolus: System Design Specification for Vattenfall ELEKTRA Project Deliverable Document, March 1998.

[Coad 1992] P. Coad Object-Oriented Patterns, Communications of the ACM, Vol. 35, No. 9 (Sep. 1992), pp. 152-159.

[Coplien 1995a] J. Coplien A Development Process Generative Pattern Language, AT\&T Bell Laboratories, WWW Publication, http://www.bell-labs.com/people/cope/Patterns/Process/index.html, 1995.

[Coplien 1995b] J. Coplien A generative Development - Process Pattern Language, in 'Pattern Languages of Program Design', J. O. Coplien and D. O. Schmidt (ed.), Addison-Wesley, pp. 183-237.

[Coplien and Schmidt 1995] J. Coplien, D. Schmidt (eds.) Pattern Languages of Program Design, Addison Wesley, Reading, MA, 1995.

[Davenport 1993] T. Davenport Process Innovation: Reengineering Work Through Information Technology, Harvard Business School Press, Boston, MA, 1993.

[DeAntonellis and Pernici 1995] V. De Antonellis and B. Pernici Reusing specifications through refinement levels, Data and Knowledge Engineering, Vol. 15, No. 2, April 1995.

[Demetra 1998] Demetra: System Design Specification for PPC ELEKTRA Project Deliverable Document, March 1998.

[Eriksson and Penker 1998] H.-E. Eriksson, M. Penker UML Toolkit, Wiley, New York, 1998. [Fowler 1997] M. Fowler Analysis Patterns: Reusable Object Models, Addison-Wesley, 1997. 
[Freja 1998] Freja: Evaluated Design for Vattenfall ELEKTRA Project Deliverable Document, October 1998.

[Gamma et al 1995] E. Gamma, R. Helm, R. Johnson, J. Vlissides Design Patterns: Elements of Reusable Object-Oriented Software, Addison Wesley, Reading, MA, 1995.

[Grosz et al. 1998] G. Grosz, P. Loucopoulos, C. Rolland, S. Nurcan A Framework for Generic Patterns Dedicated to the Management of Change in the Electricity Supply Industry, Proceedings of the 9th International Conference and Workshop on Database and Expert Systems Applications, DEXA '98.

[Hay 1996] D.C. Hay Data Model Patterns - Conventions of Thought, Dorset House Publishing, New York, 1996.

[Hsiao and Ormerod 1998] R.L. Hsiao and R.J. Ormerod A new perspective on the dynamics of information technology-enabled strategic change, Information Systems Journal, Blackwell Science, Vol. 8. No. 1 (January 1998), pp. 21-52.

[Ikarus 1998] Ikarus: Design of the ESI Toolset ELEKTRA Project Deliverable Document, March 1998.

[Kautto - Koivula 1998] K. Kautto - Koivula The Pitfalls of Knowledge, Information Strategy, July-August 1998. The Economist.

[Kavakli and Loucopoulos 1998] V. Kavakli and P. Loucopoulos Goal-driven business process analysis - Application in electricity deregulation, Proceedings of the 10th International Conference on Advanced Information Systems Engineering, CAiSE '98, May 1998, Pisa, Italy, pp. 305-324.

[Lee 1993] J. Lee Goal-Based Process Analysis: A Method for Systematic Process Redesign, Proceedings of Conference on Organizational Computing Systems, Nov. 1993, Milpitas, CA, pp. 196-201.

[Loucopoulos et al. 1997] P. Loucopoulos, V. Kavakli, N. Prekas, C. Rolland, G. Grosz, and S. Nurcan Using the EKD Approach: The Modelling Component, Research Report (ELEKTRA project), Report No. ELEKTRA/WP2/T2.1/UMIST/3, March 1997. 
[Medina-Mora et al. 1992] R. Medina-Mora, T. Winograd, R. Flores and F. Flores The ActionWorkflow Approach to Workflow Management Technology, Proceedings of Conference on Computer Supported Cooperative Work, Nov. 1992, pp. 281-288.

[Molière 1999] Molière: ESI Knowledge Base Specification ELEKTRA Project Deliverable Document, February 1999.

[Ould 1995] M.A. Ould Business Processes - Modelling and Analysis for Re-engineering and Improvement, John Wiley and Sons, Chichester, UK, 1995.

[Prekas et al. 1998] N. Prekas, P. Loucopoulos, I. Dimitromanolaki Developing Models of Reform for Electricity Supply Industry Companies, Proceedings of the 2nd IMACS International Conference on Circuits, Systems and Computers - IMACS-CSC '98, Oct. 1998, Athens, Greece, Vol. 1, pp. 337-342.

[Rolland et al. 1998a] C. Rolland, G. Grosz, P. Loucopoulos and S. Nurcan A Framework for Encapsulating Best Business Practices for Electricity Supply Industry into Generic Patterns, Proceedings of the 2nd IMACS International Conference on Circuits, Systems and Computers IMACS-CSC '98, Oct. 1998, Athens, Greece, Vol. 1, pp. 330-336.

[Rolland et al 1998b] C. Rolland, G. Grosz, S. Nurcan, W. Yue and C. Gnaho An electronic handbook for accessing domain specific generic patterns, Proceedings of the IFIP WG 8.1 Working Conference: Information Systems in the WWW Environment, July 1998, Beijing, China.

[Rolland et al 1998c] C. Rolland, S. Nurcan and G. Grosz, A Unified framework for modelling co-operative design processes and co-operative business processes, Proceedings of the $31 \mathrm{st}$ Annual International Conference on System Sciences, Big Island, Hawaii, USA, January 1998. [Scarbrough 1996] H. Scarbrough BPRC Focus Group: The relevance and Contribution of Socio-technical Systems, http://bprc.warwick.ac.uk/focus4.html. Business Processes Resource Centre, 1996.

[UP1-UMIST 1998] ELEKTRA-UP1, ELEKTRA-UMIST The Patterns Model, ELEKTRA Project Report, Report No. ELEKTRA WP5/T5.1/UP1-UMIST/2, February 1998. 
[Vlissides et al. 1996] J.M. Vlissides, J.O. Coplien and N.L. Kerth (eds.) Pattern Languages of Program Design 2, Addison-Wesley, 1996.

[Wieringa 1996] R.J. Wieringa Requirements Engineering - Frameworks for Understanding, John Wiley and Sons, Chichester, UK, 1996.

[Yu 1994] E. Yu Modelling Strategic Relationships for Process Reengineering, PhD Thesis, University of Toronto, 1994. 